www.jmscr.igmpublication.org

Impact Factor 5.84

Index Copernicus Value: 83.27

ISSN (e)-2347-176x ISSN (p) 2455-0450

crossref DOI: _https://dx.doi.org/10.18535/jmscr/v5i4.190

Journal Of Medical Science And Clinical Research

\title{
Comparison of the Induction and Recovery Characteristics of Propofol and Thiopentone Sodium for Gynaecological Diagnostic Day Case Laparoscopies Authors
}

\author{
Dr Mohan David .M ${ }^{1}$, Dr Chitra V.R ${ }^{2}$ \\ ${ }^{1}$ Assistant Professor, Govt Medical College, Palakkad \\ ${ }^{2}$ Associate Professor Govt Medical College, Thiruvananthapuram
}

\begin{abstract}
Background: Over the past three decades, outpatient surgery has grown at an exponential rate. Various surgical conditions have been diagnosed and treated using laparoscopy on a day care basis.

Aim: To study the induction characteristics like average time for induction of anaesthesia, hemodynamic effects like changes in heart rate, systolic and diastolic blood pressure, presence or absence of apnoea, involuntary movements and pain on injection,. to study recovery characteristics, incidence of postoperative nause and vomiting.

Materials and Methods: A randomized controlled double blind study involving 60 patients aged 20 to 40 years ASA PS 1 undergoing daycare laparoscopic surgery lasting less than 45 minutes. Group A received propofol $2.5 \mathrm{mg} / \mathrm{kg}$ bodyweight and group B received thiopentone sodium $5 \mathrm{mg} / \mathrm{kg}$ body weight.

Result: Our study revealed propofol to be superior to Thiopentone sodium for daycare surgery as induction agent.
\end{abstract}

Keywords: Laparosccopic surgery, Daycare anaesthesia, Propofol, Thiopentone sodium.

\section{Background}

In the recent years, there is an increasing trend of daycare surgeries as people are adopted to very busy life. The rational use of combinations of anaesthetic drugs and equipments will provide a smooth and rapid induction, excellent intraoperative conditions, and rapid reovery with minimal side effects in ambulatory anaesthesia. Intravenous anaesthetics are commonly used to induce anaesthesia as induction is more rapid and smoother than with inhalational agents.

\section{Setting of the Study}

Department of Anaesthesiology, Government Medical College, Thiruvananthapuram, was selected for the study

\section{Inclusion Criteria}

- ASA PS Class 1 patients aged 20 to 40 years

\section{Exclusion Criteria}

- Patients above 40 years

- Patients on sedative and depressive drugs

- Patients with difficult airway

- Patients with known allergy to the drugs

\section{Ethical Consideration}

Approved by ethical committee

Informed Consent

Written informed consent was obtained from all the patients after preoperative evaluation

\section{Materials and Methods}

The patients selected for the study were randomly allocated to two groups of 30 each. Group 1 
patients received propofol $2.5 \mathrm{mg} / \mathrm{kg}$ intravenously while group 2 patients received thiopentone sodium $5 \mathrm{mg} / \mathrm{kg}$ i/v for induction of anaethesia. All patients were kept nil per oral for 8 hours prior to surgery and were reassessed for fitness in the morning of surgery..

Theatre was kept ready by setting anaesthesia machine and breathing circuits. All drugs and equipments for conducting general anaesthesia and resuscitation were kept ready including laryngoscope, endotracheal tubes and resuscitation drugs. All patients were premedicated with deep intramuscular injection of Diclofenac sodium $1.5 \mathrm{mg} / \mathrm{kg}$ after test dose one hour before surgery. After securing intravenous canula $18 \mathrm{G}$, injection glycopyrrolate $5 \mathrm{microgram} / \mathrm{kg}$ was given 5 minutes prior to preoxygenation.

Monitors like ECG, NIBP, $\mathrm{SpO} 2$ were put.5minutes after premedicaation, proxygenation was done with $100 \%$ oxygen. Simultaneously patient's heart rate, systolic and diastolic BP and respiratory rate were recorded. Anaesthesia was induced with either propofol $2.5 \mathrm{mg} / \mathrm{kg}$ body weight or thiopentone sodium $5 \mathrm{mg} / \mathrm{kg}$ bodyweight given intravenously over 30 seconds. Induction time was taken as the time interval from the start of injection to loss of eyelid reflex. If reflex was present 60 seconds after the first injection, a seccond dose was given which was $50 \%$ of the first dose. Over a period of 15 seconds, the presence or absence of pain on injection, involuntary movoments, apnoea were also recorded at the time of injection. One minute after the loss of eyelid reflex, the patient's pulserate, systolic and diastolic BP and respiratory rate were recorded. 2 minutes after the loss of eyelid reflex, injection succinylcholine $2 \mathrm{mg} / \mathrm{kg}$ was given intravenously. Patient's trachea was intubated with appropriate size endotracheal tube after doing a gentle laryngoscopy. One minute after endotracheal intubation, patient's pulse rate, systolic and diastolic BP were recorded. Then inj, Vecuronium was given at a dose of $80 \mathrm{microgm} / \mathrm{kg}$ given as the non depolarising muscle relaxant. Anaesthesia was maintained wit $33 \%$ oxygen and
$66 \%$ N2O.At the end of procedure, patient was given throat suction. Inj. Neostigmine 50 microgm/kg along with Inj. Atropine 20 microgm/kg was given intravenously.N2O was discontinued. Time taken for return of eyelid reflex and time for the return of orientation (ability to tell patient's own name, name of the hospital etc). were recorded. In the recovery room, all the patients were assessed for the ability to sit up in the bed and to stand unsupported. All the patients were monitored for postoperative nausea and vomiting.

\section{Statistical Analysis and Results}

The various induction and recovery characteristics were registered and subject to various statistical analysis. The age and weight, changes in pulse rate and $\mathrm{BP}$ were tested for significance by the student's $t$ test. The significance of induction time, time taken for return of eyelid reflex, orientation and the time taken for the ability to sit up and stand unassisted were tested using nonparametric test (Kruskal-Wallis Test) for 2 groups. The significance of the incidence of apnoea at induction was tested using Yates corrected Chisquare test. The significance of the incidence of pain and involuntary movements at induction ,postoperative nausea and vomiting were tested using Fishers Exact Test. A p value <0.05 was taken as significant.

\section{Age of patients}

Table 1: Mean and Standard Deviation of age of patients in propofol and thiopentone groups and level of significance.

\begin{tabular}{|l|c|c|c|c|c|}
\hline GROUP & NUMBER & \multicolumn{2}{|c|}{$\begin{array}{c}\text { Age in years } \\
\text { Mean } \\
\text { SD }\end{array}$} & $\begin{array}{c}\text { T } \\
\text { value }\end{array}$ & $\begin{array}{c}\text { P } \\
\text { value }\end{array}$ \\
\hline propofol & 30 & 29.8 & 2.98 & 1.09 & 0.28 \\
\hline thiopentone & 30 & 28.45 & 4.66 & & \\
\hline
\end{tabular}

The difference in mean age was negligible and was not statistically signifcant. Therefore it is inferred that both the groups are identical with respect to age and hence age will not have any influence over outcome. 


\section{Weight of patients}

Table 2: Mean and SD Of weight of patients in groups 1 and 2 and level of significance.

\begin{tabular}{|l|c|c|c|}
\hline GROUP & $\begin{array}{c}\text { Weight In kg } \\
\text { Mean } \\
\text { SD }\end{array}$ & & P value \\
\hline propofol & 53.25 & \\
& 6.00 & 0.14 \\
\hline thiopentone & 53.60 & 0.88 \\
& 9.22 & \\
\hline
\end{tabular}

In group 1, it was $53.25 \mathrm{~kg}$ where as in group 2, it was $53.60 \mathrm{~kg}$. The difference in the mean weight was very negligible and was not statistically significant.

3.Table 3 Median of the induction time in groups

1 and 2

\begin{tabular}{|l|c|}
\hline GROUP & MEDIAN INDUCTION TIME \\
\hline PROPOFOL & 50 \\
THIOPENTONE & 50 \\
\hline
\end{tabular}

Nonparametric test (Kruskal-Wallus test for two groups) was applied to detect the level of significance.

Kruskal-Wallis $\mathrm{H}$ (equivalentto $\mathrm{Chi}$-square)= 0.395

Degree of freedom $=1: \mathrm{P}$ value $=0.5296$.

No statistically significant difference between the 2 groups.

\section{Change in pulserate}

a.Between 3 minutes before induction (A) and 1 minute after loss of eyelid reflex (B)

Table 4.a Mean and SD of change in pulse rate between $\mathrm{A}$ an $\mathrm{d} \mathrm{B}$ and level of significance

\begin{tabular}{|l|lr|r|c|}
\hline Group & \multicolumn{2}{|c|}{$\begin{array}{c}\text { Change in pulserate } \\
\text { between A \& B }\end{array}$} & $\begin{array}{c}\text { T } \\
\text { value }\end{array}$ & value \\
& MEAN & SD & & \\
\hline PROPOFOL & 7.2 & 3.33 & \multicolumn{2}{|c|}{0.09} \\
THIOPENTONE & 7.3 & 3.91 & 0.93 \\
\hline
\end{tabular}

It is evident that the change in pulse rate in the two groups are almost equal and the difference in pulse rate was statistically insignificant.

b.Between one minute after loss of eyelid reflex (B) and 1 minute after intubation $(\mathrm{C})$

Table 4.b Mean and SD of change in pulse rate between $B$ and $C$ and level of significance

\begin{tabular}{|c|c|c|c|}
\hline GROUP & $\begin{array}{c}\text { Change in pulse rate } \\
\text { between } B \text { \& C }\end{array}$ & $\begin{array}{c}\mathrm{T} \\
\text { value }\end{array}$ & $\begin{array}{c}\mathrm{P} \\
\text { value }\end{array}$ \\
\hline & Mean $\quad$ SD & & \\
\hline PROPOFOL & $\begin{array}{l}18.8 \\
7.63\end{array}$ & \multirow{2}{*}{\multicolumn{2}{|c|}{$\begin{array}{l}1.23 \\
0.22\end{array}$}} \\
\hline THIOPENTONE & $\begin{array}{l}15.7 \\
8.24\end{array}$ & & \\
\hline
\end{tabular}

In group 1 , the mean change in pulse rate between 1 minute after loss of eyelid reflex and 1 minute after intubation was 18.8 beats/minute, whereas it was 15.7 beats /minute in group 2.However the difference in the change in pulse rate between the two groups was not significant statistically.

\section{Change in systolic blood pressure}

a. Between 3 minutes before induction (A) and 1 minute after 1minute after loss of eyelid reflex(B)

Table 5.a Mean and SD of change in systolic blood pressure between $\mathrm{A}$ and $\mathrm{B}$ and level of significance

\begin{tabular}{|l|lr|c|c|}
\hline GROUP & \multicolumn{2}{|c|}{$\begin{array}{c}\text { Change in SBP } \\
\text { between A \& B }\end{array}$} & \multirow{2}{*}{$\begin{array}{c}\text { T } \\
\text { value }\end{array}$} & value \\
& Mean & SD & & \\
\cline { 1 - 2 } PROPOFOL & 20.6 & 8.99 & 4.26 & \multirow{2}{*}{0.0001} \\
\hline THIOPENTONE & 11.1 & 4.33 & & 0.0001 \\
\hline
\end{tabular}

In group 1, the mean change in systolic blood pressure between 3 minutes before induction and 1 minute after loss of eyelid reflex was $20.6 \mathrm{~mm}$ of $\mathrm{Hg}$, were as it was $11.1 \mathrm{mmHg}$ in group 2. The difference in the change in systolic blood pressure between the two groups was statistically significant. In other words, induction of anaesthesia with propofol produced significant decrease in systolic blood pressure compared to induction of anaesthesia with thiopentone

b. Between one minute after loss of eyelid reflex(B) and one iminute after intubation $(C)$

Table 5,b Mean and SD of change in SBP, between $B$ and $C$ and level of significance

\begin{tabular}{|l|lr|c|c|}
\hline GROUP & \multicolumn{2}{|l|}{$\begin{array}{l}\text { Change in SBP } \\
\text { between B \& C }\end{array}$} & T value & P value \\
& Mean & SD & & \\
\hline PROPOFOL & 30.5 & 9.84 & \\
THIOPENTONE & 22.4 & 9.57 & 2.64 \\
& & & & 0.01 \\
\hline
\end{tabular}

In group 1, the mean change in SBP between one minute after loss of eyelid reflex and 1 minute after. intubation was $30.5 \mathrm{~mm}$ of $\mathrm{Hg}$, where as in group 2,it was $22,4 \mathrm{~mm}$ of $\mathrm{Hg}$. The difference in the change in SBP between the two groups was statistically significant. This shows that intubation of the trachea produce significant increase in SBP.

\section{Change in diastolic blood pressure}

a.Between 3 minutes before induction (A) and 1 minute after loss of eyelid reflex (B) 
Table 6.a Mean and SD of change in diastolic Blood pressure (DBP) between A and B and level of significance

\begin{tabular}{|l|c|c|c|}
\hline Group & $\begin{array}{c}\text { Change in } \\
\text { DBP between }\end{array}$ & T value & P value \\
& A \& B & & \\
& Mean & & \\
& SD & \\
\hline PROPOFOL & 7.6 & \multicolumn{2}{|c|}{0.44} \\
& 4.23 & \multicolumn{2}{|c|}{0.66} \\
\hline THIOPENTONE & 7.1 & \\
& 2.71 & \\
\hline
\end{tabular}

So statistically no significant difference between the two groups

$\mathrm{B}$, Between one minute after loss of eyelid reflex (B) AND 1 minute after intubation (C)

Table 6.b Mean and SD of change in DBP between $\mathrm{B}$ and $\mathrm{C}$ and level of significance

\begin{tabular}{|l|c|c|c|}
\hline GROUP & \multicolumn{2}{|c|}{$\begin{array}{c}\text { Change in DBP } \\
\text { between B \& C } \\
\text { Mean value }\end{array}$} & P value \\
\hline PROPOFOL & 14.1 & & 0.4 \\
& 4.88 & 0.69 \\
THIOPENTONE & 14.7 & \\
\hline
\end{tabular}

Stastically no significant difference between the two groups

7. Incidence of apnoea at induction of anaesthesia

Table 7 Distribution of cases aaccording to the incidence of apnoea at induction of anaesthesia

\begin{tabular}{|l|c|c|}
\hline GROUP & $\begin{array}{c}\text { Apnoea } \\
\text { Present }\end{array}$ & Total No. \\
\hline PROPOFOL & 12 & 30 \\
\hline THIOPENTONE & 4 & 30 \\
\hline
\end{tabular}

Yates corrected Chi squares $=5.1$

Degree of freedom $=p$ Value $=0.0239$

In group 1, 12 patients experienced apnoea at induction of anaesthesia, whereas in group2,4 patients experienced apnoea at induction. The differnce in the incidence of apnoea was statistically significant. This shows that in the present study, induction of anaesthesia with propofol caused significant incidence of apnoea compared to induction with thiopentone.

8. Pain on intravenous injection of the induction agent

Table 8

\begin{tabular}{|l|c|c|}
\hline GROUP & Pain on injection & Total No \\
\hline PROPOFOL & 6 & 30 \\
\hline THIOPENTONE & 0 & 30 \\
\hline
\end{tabular}

Fishers exact test $\mathrm{P}$ value $=0.0202$
In group 1,6 patients experienced pain where as in group 2, none had pain. This is statistically significant. Propofol causes significant incidence of pain when compared to thiopentone.

9. Incidence of involuntary movements at induction of anaesthesia

Table 9

\begin{tabular}{|l|c|c|}
\hline GROUP & $\begin{array}{c}\text { Involuntary } \\
\text { Movements }\end{array}$ & $\begin{array}{c}\text { Total } \\
\text { No }\end{array}$ \\
\hline PROPOFOL & 8 & 30 \\
\hline THIOPENTONE & 0 & 30 \\
\hline
\end{tabular}

Fishers Exact Test $\mathrm{p}$ value $=0.0033$

Induction with propofol caused increased incidence of involuntary movements.

\section{Time taken for return of eyelid reflex}

Table 10 Median time taken for the return of eyelid reflex (RELR)

\begin{tabular}{|l|c|}
\hline GROUP & Median time for RELR(seconds) \\
\hline Propofol & 40 \\
Thiopentone & 105 \\
\hline
\end{tabular}

Kruskall-Wallis $\mathrm{H}$ test for two groups was applied to detect the level of significance.

Kruskal-Wallis $\mathrm{H}$ (equivalent to $\mathrm{Chi}$ square)= 27.696

Degree of freedom $=1$

$\mathrm{P}=0.0000$

In group 1, the median time taken for eyelid reflex was 40 seconds, whereas it was 105 seconds in group 2.The difference in the time taken for eyelid reflex was statistically significant. This means that the patients in propofol group took significantly lesser time for return of eyelid reflex compared to thiopentone group.

\section{Time taken for return of orientation}

\section{Table 11}

\begin{tabular}{|l|c|}
\hline Group & $\begin{array}{c}\text { Median time taken for return } \\
\text { of orientation(sec) }\end{array}$ \\
\hline $\begin{array}{l}\text { Propofol } \\
\text { Thiopentone }\end{array}$ & 90 \\
180 \\
\hline
\end{tabular}

Kruskall $=$ Wallis $\mathrm{H}$ (equivalent to $\mathrm{Chi}$ square)= 22.046

Degree of freedom $=1$

$P$ value $=0.000003$

In group1, the median time taken for return of orientation was 90 seconds. In group 2, it was 180 seconds. The difference in time taken was statistically significant. In other words, patients in propofol group took significantly lesser time for 
return of orientation compared to patients in thiopentone group.

\section{Time taken for the ability to sit up unassisted}

Table 12 Median time for the ability to sit up unassisted

\begin{tabular}{|l|c|}
\hline Group & Median time to situp(minutes) \\
\hline Propofol & 97.5 \\
Thiopentone & 187.5 \\
\hline
\end{tabular}

Kruskall-Wallis $\mathrm{H}$ (equivalent to Chisquare)= 29.48

Degree of freedom $=1$

$P$ value $=0.0000$

In group 1,the median time taken for the ability to sit up unassisted was 97.5 minutes, where as it was 187.5 minutes in group 2 .The difference in ability to sit up was statistically significant.

Table 13 Median time taken for the ability to stand up unassisted

\begin{tabular}{|l|l|}
\hline Group & $\begin{array}{l}\text { Median time for ability to } \\
\text { stand up(minutes) }\end{array}$ \\
\hline Propofol & 120 \\
Thiopentone & 210 \\
\hline
\end{tabular}

Kruskal-Wallis $\mathrm{H}$ (equivalent to Chisquare)= 29.495

Degree of freedom $=1$

$P$ value $=0.0000$

In the group1, the median time for the ability to standup unassisted was 120 minutes, whereas in group2,it was 210 minutes. The difference was statistically significant. Patients in the propofol group took significantly lesser time for the ability to stand up than patients in thiopentone group.

14. Incidence of postoperative nausea andvomiting (PONV)

\begin{tabular}{|l|l|}
\hline Group & $\begin{array}{l}\text { Present } \\
\text { Total No }\end{array}$ \\
\hline Propofol & 30 \\
Thiopentone & 8 \\
& 30 \\
\hline
\end{tabular}

Fishers Exact Test $\mathrm{P}$ value $=0.0197$

Difference in the incidence of PONV was statistically significant. This clearly shows the antiemetic property of propofol.

\section{Discussion}

Daycare anaesthesia require an agent that produces rapid onset of anaesthesia and quick return to discharge state within a short time. This study was a randomized double blind between patients involving 60 ASA PSC 1 patients for daycare procedures. They were allocated into two random groups .One group received propofol as induction agent while second group received thiopetone as induction agent. The induction agent was given by an assistant into a vein under cover hidden from the aneaesthesiologist. Thus neither the patient nor the anaesthesiologist who recorded and interpreted the data were aware of the induction agent used.

The various induction and recovery characteristics were registered and subject to statistical analysis. The results of the present study have shown that both the groups were identical with respect to age and weight of the patients and these parameters will not have any influence over the outcome. Induction of anaesthesia was rapid and reliable with both propofol and thiopentone without any serious untoward effects.

The median induction time in this study was 50 seconds in both the groups as there was no statistically significant difference between the groups. In a study conducted by Mac Kenzie et al, the median induction time with propofol at a dose of $2.5 \mathrm{mg} / \mathrm{kg}$ was 30.6 seconds and that with thiopentone sodium at a dose of $5 \mathrm{mg} / \mathrm{kg}$ was 29.6 seconds. The finding of the present study correlate with the above study.

In the present study, induction of anaesthesia resulted in a reduction in pulse rate in both groups. The mean reduction in pulse rate was 7.2 beats per minute in the propofol group and 7.3 beats per minute in the thiopentone group and there was no statistical difference. Lippmann $\mathrm{M}$ et al have found that heart rate increases after an induction dose of thiopentone and remains unchanged after an induction of propofol. In the present study, endotracheal intubation resulted in an increase in pulserate in both groups. The mean increase in pulserate was 18.8 beats per minute in the propofol group and 15.7 beats per minute in the thiopentone group which was not statistically significant. 
Induction of anaethesia resulted in a decrease in systolic blood pressure in both the groups in the present study. The mean decrease was $20.6 \mathrm{mmHg}$ in propofol group and $11.1 \mathrm{mmHg}$ in Thiopentone group and the difference in the mean decrease in tne systolic blood pressure was statistically significant. This finding correlates with the observation made by Boysen et al who found that with induction of anaesthesia, systolic BP decreased by $15 \mathrm{mmHg}$ in the Propofol group and $3 \mathrm{mmHg}$ in the Thiopentone group. In the present study, endotracheal intubation resulted in an increase in systolic bloodpressure in both the groups. The mean increase was $30.5 \mathrm{mmHg}$ in the Propofol group and $22.4 \mathrm{mmHg}$ in the Thiopentone group and the difference was statistically significant. Van Aken $\mathrm{H}$ et al found that induction of anaesthesia with Propofol alone resulted in moderate increase in systolic blood pressure which can be attenuated by administation of fentanyl.

In the present study, induction of anaesthesia resulted in a decrease in diastolic blood pressure in both the groups. The mean decrease was 7.6 $\mathrm{mmHg}$ in the Propofol group and $7.1 \mathrm{mmHg}$ in the Thiopentone group and the difference in the mean decrease in the diastolic blood pressure was not statistically significant. Fahy et al have found that there is a significant decrease in diastolic blood pressure after induction with Propofol.

In the present study, endotracheal intubation resulted in an decrease in diastolic blood pressure in both the groups. The mean increase was 14.1 $\mathrm{mmHg}$ in the Propofol group and $14.7 \mathrm{mmHg}$ in the Thiopentone group and the mean increase in diastolic bp was not statistically significant. In the present study, the incidence of apnoea at induction was $60 \%$ in the Propofol group wher as it was $20 \%$ in the Tthiopentone group which was statistically significant. Grounds R M et al have found that there is no significant difference in the incidence of apnoea at induction whether anaesthesia was induced with Propofol or Thiopentone. Taylor et al showed propofol caused
$65 \%$ incidence of apnoea at induction whereas Thiopentone caused $45 \%$ incidence.

In the present study, $30 \%$ patients in the Propofol group experienced pain on intravenous injection of Propofol. None of the patients in the Thiopentone group experienced pain on intavenous injection of Thiopentone. The difference was stastistically significant. Stark R.D et al have found an increased incidence of pain on injection of Propofol.In a study done by De Grood PMRM et al, injection of Propofol resulted in 32\% incidence of pain whereas injection of Thiopentone caused $7 \%$ incidence of pain.

In the present study,the incidence of involuntary movements was $40 \%$ in th Propofol group whereas none experienced involuntary movements in the Thiopentone group. The difference wsa statitically significant. Boysen et al and Mirakhur R.K et al have found that occurrence of involuntary movements was almost equal in both the groups.

Recovery from anaesthesia was rapid, smooth and clear headed with Propofol. In the present study, the median time taken for the return of eyelid reflex was 40 seconds in the Propofol group, whereas it was 105 seconds in the Thiopentone group, the difference was statistically significant. In a study done by Weightmann et al, the mean time taken for return of eyelid reflex was 5.4 minutes in the Propofol group wheras it was 12.3 minutes in the Thiopentone group. ( $p, 0.001)$

In the present study, the median time taken for return of orientation was 90 seconds in the Propofol group whereas it was 180 seconds in thr Tthiopentone group. The difference was stastistically significant in a study done by Korttila $\mathrm{K}$ et al, the mean time taken for return of orientation was 5.7 minutes in the Propofol group whereas it was 10 minutes in the Thiopentone which was statistically signifant. Rashiq et al have found that the mean time taken for return of orientation was 8.8 minutes in Propofol group and 10.9 minutes in the Thiopentone group ( $p, 0.05)$

In the present study, the median time taken for the ability to situp un assisted was 97.5 minutes in the 
Propofol group and 187.5 minutes in the Thiopentone group. The difference was statistically significant. In a study done by Korttila et al, the mean tie taken for the ability to situp unassisted was 58 minutes in the Propofol group wheras it was 77 minutes in the Thiopentone group which was statistically significant.

The median time taken for the ability to stand up un assisted in te present study, was 120 minutes. In a study doneby Korttila et al, the mean time taken for the ability to standup unassisted was 66 minutes in the Propofol group whereas it was 92 minutes in the Thiopentone group which was statistically significant. In a study done by Weightman et al, the mean time taken for the ability to stand up unassisted was 129 minutes in the Propofol group and 218 minutes in the Thiopentone group $(\mathrm{p}, 0.001)$

In the present study, the incidence of postoperative nausea and vomiting was $5 \%$ in the Propofol group whereas it was $40 \%$ in the Thiopentone group. The difference was statistically significant. In a study done by Korttila et al, the incidence of of nausea and vomiting was $35 \%$ in the Propofol group and $75 \%$ in the other group.(p,0.05).

\section{Conclusion}

Induction of anaesthesia was rapid and reliable with both Propofol and Thiopentone. Although induction with Propofol resulted in significant incidence of apnoea, involuntary movements, pain on injection,and fall in systolic blood pressure, it presented no serious clinical problems. Propofol was associated with faster, smoother and clearheaded recovery and lesser incidence of PONV. Hence from the present study, it can be safely concluded that Propofol is a better alternative to Thiopentone for day care procedures.

\section{References}

1. Barker p,Langton J A,Murphy P, Rowbotham DJ. Effect of prior administration of cold saline on pain durinf propofol injection.Anaesthesia46:1069-70;1991

2. Berggren L,Eriksson I, Midazolam for induction of anaesthesia in outpatients :a comparison with Thiopentone .Acta Anaesthesiologica Scandinavica 25;49206;1981

3. Borgeat A,Wilder Smith $\mathrm{OH}$,Saiah $\mathrm{M}$, Rifat K.Subhypnotic doses of propofol possess direct antiemetic properties AN Aesthesia and Analgesia 74:539-41;1992

4. Chittleborough MC,Osborne GA,Rudkin GA,Vickers D.Double blind comparison of patient recovery after binduction with thiopentone or propofol for day care relaxant GAAnaesthesia and Intensive acare 20;169-73;1992

5. Cooper GM Recovery from anaesthesia, Clinics in Anaesthesiology $2 ; 145-62 ; 1984$

6. Cullen P.M,Turtle M,Prys Roberts .Effect of propofol anaesthesia on baroreflex activity in humans Anaesthesia and Analgesia 66;1115,1987

7. De GroodP.M.R.M,Harbers JBM et al. Anaesthesia for laparoscopy. A compaarison of five techniques incldinf propofol, etomidate, thiopentone and isoflurane anaesthesia 42;815.1987

8. Dundee JW. Intravenous anaesthesia and need for new agents. Postgraduate Medical Journal 3-6,1985

9. Edelist $\mathrm{G}$;Acomparison of propofol and thiopentone as induction agent in outpatient surgery Canadian Journal of Anaesthesia 34;110-6;1987

10. Gan TJ,Ginsberg B, Grant AP et al;Adouble blind randomized comparison of ondansetron and intraoperative propofol to prevent potoperative nausea and vomiting anaesthesiology85;1036,1996

11. Grounds RM.Twigley AJ,Carli F; the hemodynamic effects of thiopentone and propofol Anaesthesia 40.735,1985

12. Hudson R J,Stanski DR,Burch PG; Pharmacokinetics of methohexital and 
thiopentone in surgical patients

Anaesthesiology 59;215.1983

13. Korttila K,Anaesthesia for day surgery. Recovery and discharge.Acta Anaesthesiologica Scandinavica,35 108-113,1991

14. Ogg T W.Assessment of postoperative outpatient cases British Medical Journal 4 ;573-6, 1972.

15. Stark RD,Binks SM,Dukka VN,;A review of the safety and tolerance of prpofol, Postgraduate Medical Journal 61;152,1985 